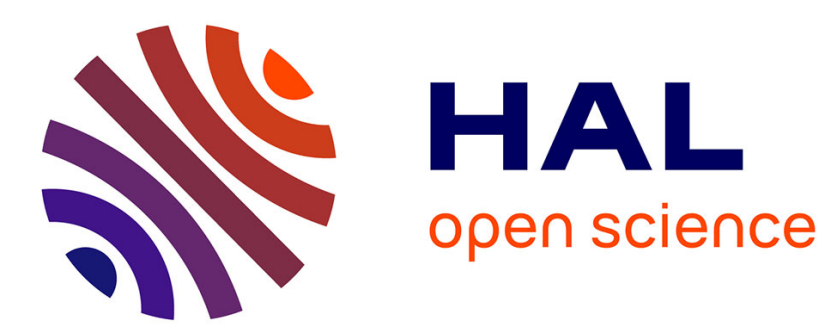

\title{
Normally-off AlGaN/GaN MOS-HEMT using ultra-thin Al0.45 Ga0.55N barrier layer
}

Ahmed Chakroun, Abdelatif Jaouad, Meriem Bouchilaoun, Osvaldo Arenas, Ali Soltani, Hassan Maher

\section{- To cite this version:}

Ahmed Chakroun, Abdelatif Jaouad, Meriem Bouchilaoun, Osvaldo Arenas, Ali Soltani, et al.. Normally-off AlGaN/GaN MOS-HEMT using ultra-thin Al0.45 Ga0.55N barrier layer. physica status solidi (a), 2017, 214 (8), 10.1002/pssa.201600836 . hal-01914374

\section{HAL Id: hal-01914374 \\ https://hal.science/hal-01914374}

Submitted on 16 Nov 2018

HAL is a multi-disciplinary open access archive for the deposit and dissemination of scientific research documents, whether they are published or not. The documents may come from teaching and research institutions in France or abroad, or from public or private research centers.
L'archive ouverte pluridisciplinaire HAL, est destinée au dépôt et à la diffusion de documents scientifiques de niveau recherche, publiés ou non, émanant des établissements d'enseignement et de recherche français ou étrangers, des laboratoires publics ou privés. 


\title{
Normally-off AIGaN/GaN MOS-HEMT using ultra-thin $\mathrm{Al}_{0.45} \mathrm{Ga}_{0.55} \mathrm{~N}$ barrier layer
}

\author{
Ahmed Chakroun, Abdelatif Jaouad, Meriem Bouchilaoun, Osvaldo Arenas, Ali Soltani, and Hassan \\ Maher
}

Laboratoire Nanotechnologies Nanosystèmes (LN2) - CNRS UMI-3463 - Institut Interdisciplinaire d'Innovation Technologique (3IT), Université de Sherbrooke, 3000 Boulevard de l'université, Sherbrooke, QC J1 K OA5, Canada

\begin{abstract}
In this work, we report on the fabrication of a normally-off AlGaN/GaN Metal-Oxide-Semiconductor High Electron Mobility Transistor (MOS-HEMT) using an ultra-thin $\mathrm{Al}_{0.45} \mathrm{Ga}_{0.55} \mathrm{~N}$ barrier layer. The $\mathrm{AlGaN}$ barrier was thinned down to $1 \mathrm{~nm}$ using a digital etching process (Oxidation/ Etching) and was followed by a PECVD deposition technique of a $7 \mathrm{~nm}$ thick $\mathrm{SiO}_{\mathrm{x}}$ layer used as gate insulator. Thanks to the thin AlGaN barrier layer $(4 \mathrm{~nm})$, only a few digital etching
\end{abstract}

cycles are required to shift the threshold voltage toward positive values. The fabricated normally-off device exhibits a pinch-off voltage of $+1.1 \mathrm{~V}$, a maximum $I_{\mathrm{DS}}$ current of $460 \mathrm{~mA} \mathrm{~mm}^{-1}$ at $V_{\mathrm{GS}}=+5 \mathrm{~V}$, an On-state resistance $\left(R_{\mathrm{ON}}\right)$ of $7.8 \Omega \cdot \mathrm{mm}$ and an $I_{\mathrm{ON}} / I_{\mathrm{OFF}}$ ratio higher than $10^{9}$. Moreover, the pulsed $I_{\mathrm{DS}}-V_{\mathrm{DS}}$ and capacitance-voltage $(C-V)$ curves versus frequency confirm that there is no damage induced by the digital etching process.

Keywords AlGaN, digital etching, GaN, high electron mobility transistors, metal-oxide-semiconductor structures, passivation

1 Introduction Thanks to its superior fundamental properties, Gallium Nitride $(\mathrm{GaN})$ has received extensive attention for high power and high frequency applications. AlGaN/GaN High Electron Mobility Transistors (HEMTs) have demonstrated tremendous potential due to their high sheet carrier density and 2DEG electron mobility. Standard AlGaN/GaN HEMT structures have a negative threshold voltage $\left(V_{\mathrm{TH}}\right)$, giving a "normally-on" operation mode. One of the major challenges for GaN-HEMTs power devices is the achievement of an enhancement-mode device "normally-off," required for a simpler drive circuitry and safer operation [1].

Several techniques have been reported in order to shift the threshold voltage toward positive values. The most cited ones are: fluorine $\left(\mathrm{F}^{-}\right)$ion implantation [1-4], AlGaN barrier recess [5-8], and p-GaN (or p-AlGaN) gated structure [9-10]. The gate recess approach by dry etching has been largely used but it suffers from a non-uniformity recess depth and a high plasma induced damage, which considerably deteriorates the electron mobility in the channel and the device reliability [11]. To avoid the plasma induced damage, some works reported on the use of digital etching process to etch the $\mathrm{AlGaN}$ barrier layer. This consists of barrier oxidation using a soft oxygenbased plasma followed by a wet-chemistry removal of the formed oxide layer [12]. The major drawback of this technique is the extremely low etching rate $(\sim 5 \AA /$ cycle $)$. Sixty-three Oxidation/Etching cycles have been used to etch a $24 \mathrm{~nm}$ thick AlGaN barrier [12]. In addition, the reported MOSHEMT device exhibits a large hysteresis $(\sim 0.7 \mathrm{~V})$, suggesting a deficient $\mathrm{Al}_{2} \mathrm{O}_{3} / \mathrm{GaN}$ interface with an estimated interface traps density $\left(D_{\mathrm{it}}\right)$ of $2.6 \times 10^{12} \mathrm{eV}^{-1} \cdot \mathrm{cm}^{-2}$ [12].

In this work, we report on the achievement of a normally-off $\mathrm{AlGaN} / \mathrm{GaN}$ MOS-HEMT by using an ultrathin $\mathrm{Al}_{0.45} \mathrm{Ga}_{0.55} \mathrm{~N}$ barrier and a digital etching process followed by an optimized $\mathrm{PECVD}-\mathrm{SiO}_{\mathrm{x}}$ passivation procedure. Thanks to the initially thin $\mathrm{Al}_{0.45} \mathrm{Ga}_{0.55} \mathrm{~N}$ barrier $(4 \mathrm{~nm})$, only six Oxidation/Etching cycles are needed to shift the threshold voltage toward positive values. The fabricated device exhibits stable characteristics, with a positive pinch-off voltage of $+1.1 \mathrm{~V}$, an $I_{\mathrm{DS}}$ current of $460 \mathrm{~mA} \mathrm{~mm}^{-1}$ at $V_{\mathrm{GS}}=+5 \mathrm{~V}$ and a gate leakage current below $1 \mathrm{nA} \mathrm{mm}^{-1}$. Based on the hysteresis measurements, the extracted $D_{\mathrm{it}}$ was 
estimated to be as low as $1.49 \times 10^{11} \mathrm{~cm}^{-2} \mathrm{eV}^{-1}$. This showcases the low damage induced by the digital etching technique and the efficiency of the proposed passivation process.

2 Experimental The AlGaN/GaN MOS-HEMTs were fabricated on commercial HEMT wafers (supplied by EpiGaN) grown by Metal-Organic Chemical Vapor Deposition (MOCVD) on a Si substrate. The epitaxial structure consists of an $\mathrm{Al}_{0.08} \mathrm{Ga}_{0.92} \mathrm{~N}$ back barrier layer, a $150 \mathrm{~nm}$ undoped $\mathrm{GaN}$ channel layer and a thin $4 \mathrm{~nm}$ $\mathrm{Al}_{0.45} \mathrm{Ga}_{0.55} \mathrm{~N}$ barrier layer. The epitaxial structure was finally capped with a $50 \mathrm{~nm}$ in situ SiN layer. The fabrication process begins by dry-etching the in situ $\mathrm{SiN}$ layer before the e-beam evaporation of the ohmic contact metal stack (Ti/Al/Ni/Au). Rapid thermal annealing was then performed at $875^{\circ} \mathrm{C}$ for $30 \mathrm{sec}$ in $\mathrm{N}_{2}$ ambient. Device isolation was achieved by nitrogen ion implantation. For the gate electrode, the $50 \mathrm{~nm} \mathrm{SiN} \mathrm{cap} \mathrm{layer} \mathrm{was} \mathrm{first} \mathrm{etched} \mathrm{using}$ very low power $(5 \mathrm{~W}) \mathrm{SF}_{6}$-based ICP plasma. The revealed $\mathrm{AlGaN}$ layer, in the gate area, was then oxidized using an $\mathrm{O}_{2}$ plasma asher for $2 \mathrm{~min}$. The sample was then dipped in an $\mathrm{HCl}: \mathrm{H}_{2} \mathrm{O}(1: 10)$ solution for $1 \mathrm{~min}$ to remove the formed oxide layer. After six digital etching cycles, the $\mathrm{AlGaN}$ barrier was thinned down to near $1 \mathrm{~nm}$, as confirmed by Atomic Force Microscopy (AFM) shown in Fig. 1(b). A control sample, without digital recess, was also fabricated as a reference. Both samples were then cleaned and annealed at $420{ }^{\circ} \mathrm{C}$ for $20 \mathrm{~min}$ under a $\mathrm{N}_{2}$ ambient to desorb the $\mathrm{F}^{-}$ions from the AlGaN surface [13]. Prior to the gate dielectric layer deposition, the samples were pretreated using a $\mathrm{KOH}$ solution, followed by an immersion in $\mathrm{HCl}$ for $2 \mathrm{~min}$. A $7 \mathrm{~nm}$ thick PECVD-SiO ${ }_{\mathrm{x}}$ layer was then deposited as a gate insulator using the passivation process previously reported in [14]. Finally, a Ni/Au (40/600 nm) gate metal stack was deposited by e-beam evaporation. Fig. 1(a) illustrates a schematic of the fabricated MOS-HEMT device using digital etching process. The etching rate, extracted from the Atomic Force Microscopy (AFM) analyses, is about $5 \mathrm{~A} /$ cycle, as can be seen in Fig. 1(b). Electrical characterizations were performed using a Keithley 4200SCS analyzer.

3 Results and discussion Figure 2 shows the DC output characteristics for the fabricated $\mathrm{AlGaN} / \mathrm{GaN}$
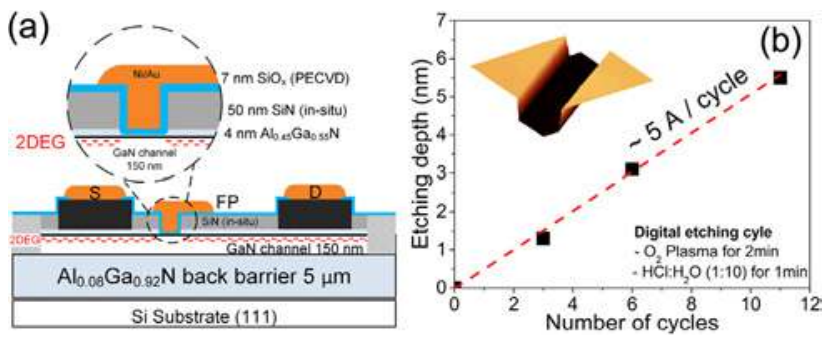

Figure 1 (a) Schematics of the fabricated MOS-HEMT and (b) digital etching depth versus digital etching cycles.
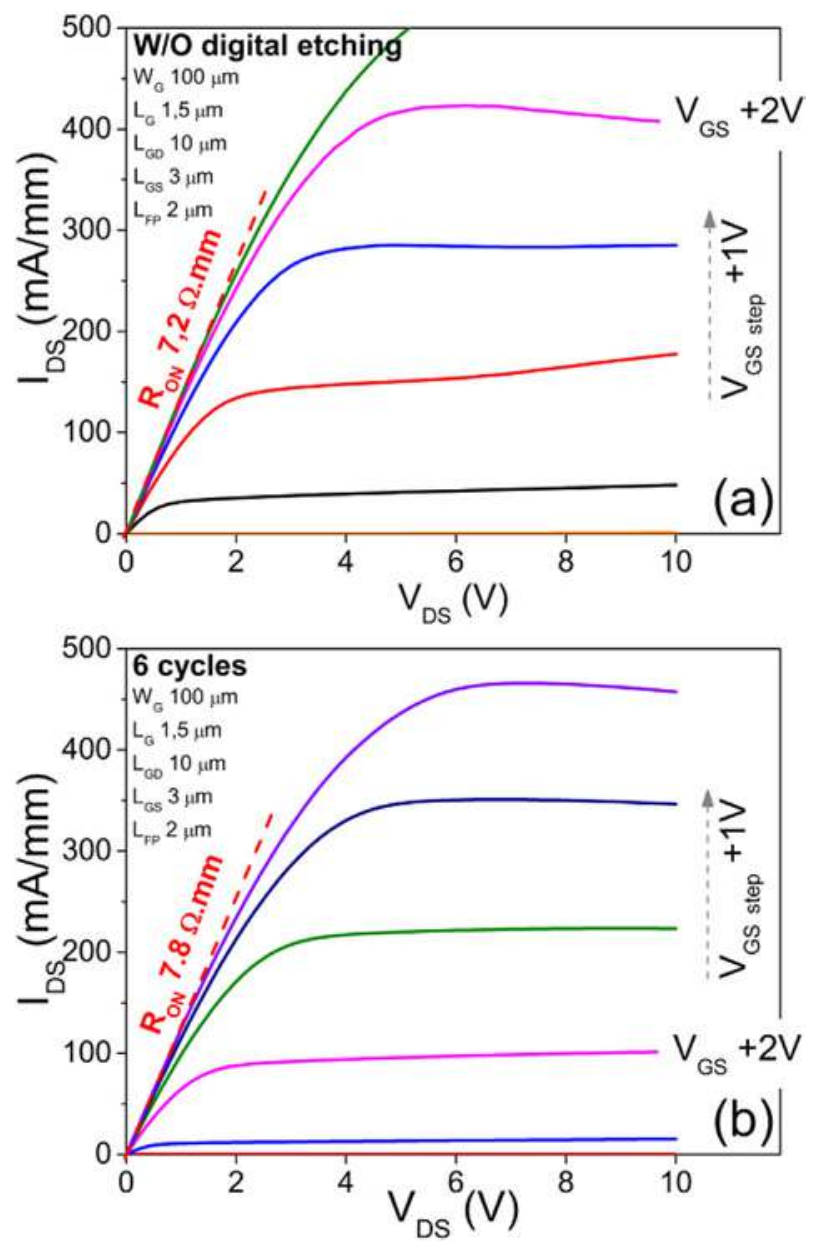

Figure $2 I_{\mathrm{DS}}-V_{\mathrm{DS}}$ characteristic measured on fabricated MOS-HEMTs (a) W/O digital etching (reference) and (b) with six cycles.

MOS-HEMTs with a $1.5 \mu \mathrm{m}$ gate length, a $10 \mu \mathrm{m}$ gateto-drain distance, a $3 \mu \mathrm{m}$ gate-to-source distance, and a $2 \mu \mathrm{m}$ field plate length. The MOS-HEMT device, fabricated on a reference sample, without digital etching (Fig. 2(a)), demonstrates a normally-on operation with a pich-off voltage of $-1.2 \mathrm{~V}$ and an On-state resistance $\left(R_{\mathrm{ON}}\right)$ of $7.2 \Omega \cdot \mathrm{mm}$. The MOS-HEMT with six cycles of digital etching shows a normally-off operation with a drain current density of $460 \mathrm{~mA} \mathrm{~mm}^{-1}$ at $V_{\mathrm{GS}}=+5 \mathrm{~V}$ (Fig. 2(b)). The extracted $R_{\mathrm{ON}}$ is slightly higher, about $7.8 \Omega \cdot \mathrm{mm}$, showing that no significant surface degradation was induced by digital etching on the device $R_{\mathrm{ON}}$.

Figure 3 shows the device hysteresis transfer characteristics $\left(I_{\mathrm{DS}}-V_{\mathrm{GS}}\right)$ at $V_{\mathrm{DS}}=10 \mathrm{~V}$. The pinch-off voltage $\left(V_{\mathrm{p}}\right)$ was shifted from -1.2 to $+1.1 \mathrm{~V}$ after six cycles of digital etching. The maximum $G_{\mathrm{m}}$ peaks, measured on both devices, were about $130 \mathrm{mS} \mathrm{mm}^{-1}$ as can be seen in Fig. 3 (a). The threshold voltage $\left(V_{\mathrm{TH}}\right)$ measured at $I_{\mathrm{DS}}=1 \mathrm{~mA} \mathrm{~mm}^{-1}$ was shifted from -1.9 to $+0.3 \mathrm{~V}$ after AlGaN barrier thinning as can be seen in Fig. 3(b). A low hysteresis was observed in both samples on (a) linear and (b) 

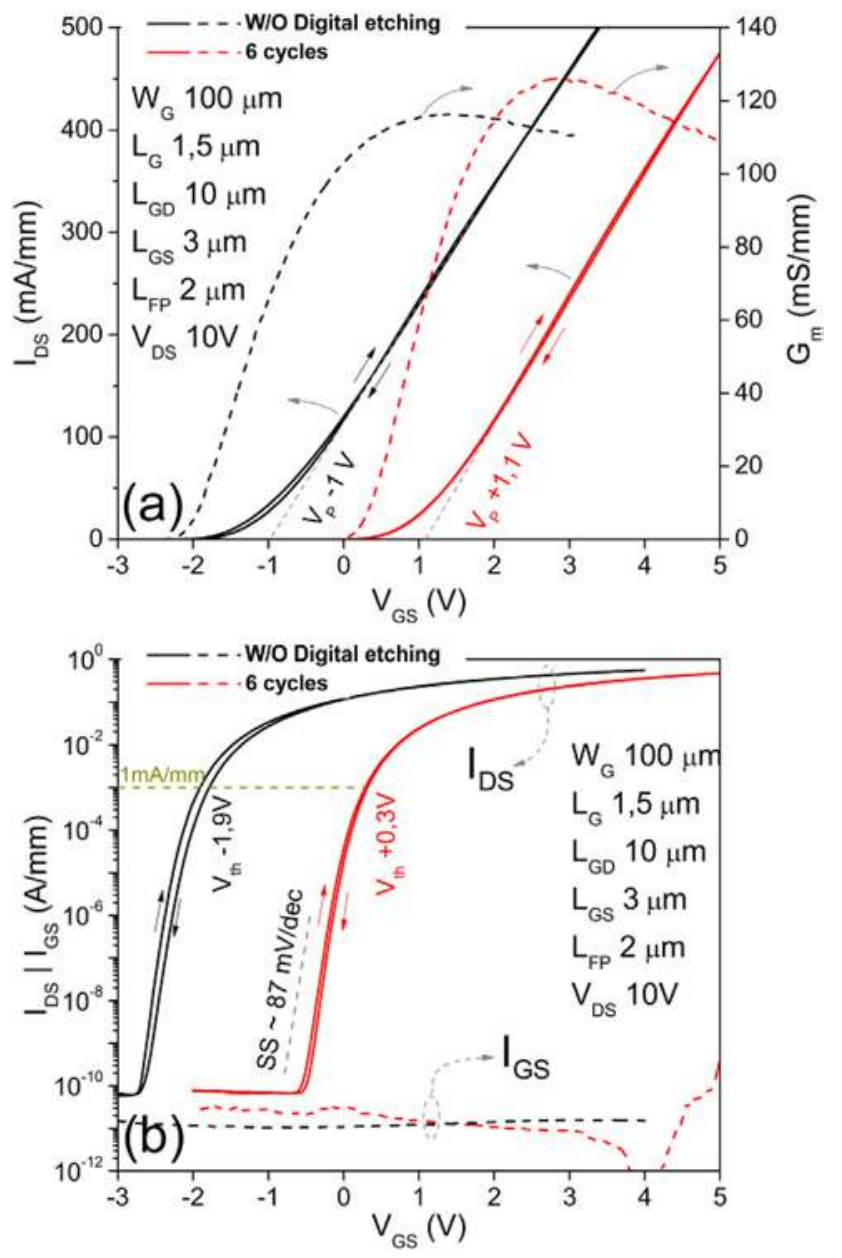

Figure 3 (a) Linear and (b) semi-logarithmic transfer characteristics $I_{\mathrm{DS}}-V_{\mathrm{GS}}$ of the fabricated MOS-HEMTs device.

semi-logarithmic scale $I_{\mathrm{DS}}-V_{\mathrm{GS}}$ curves. This demonstrates the efficiency of the gate recess and the passivation processes. Moreover, thanks to the high quality of the $7 \mathrm{~nm}$ PECVD-SiO ${ }_{x}$ gate insulator, the device exhibits a low gate leakage current. For the whole measurement range, the maximum gate leakage current $\left(I_{\mathrm{GS}}\right)$ is below $1 \mathrm{nA} \mathrm{mm}^{-1}$. Furthermore, the off-state drain leakage current is also below $1 \mathrm{nA} \mathrm{mm}{ }^{-1}$, giving an $I_{\mathrm{ON}} / I_{\mathrm{OFF}}$ ratio higher than $10^{9}$. The sub-threshold slope (SS) extracted from the transfer characteristic is about $87 \mathrm{mV} \mathrm{dec}^{-1}$ for both devices, as can be seen in Fig. 3(b).

Circular MOS capacitors, with a $100 \mu \mathrm{m}$ diameter, were also fabricated on both samples. Figure 4 shows the hysteresis capacitance-voltage $\left(C_{\mathrm{GS}}-V_{\mathrm{GS}}\right)$ measurements performed at frequency ranged from 10 to $100 \mathrm{kHz}$. Both devices show good surface potential modulation with very low hysteresis. MOS capacitor fabricated on the control sample, without digital etching, shows a maximum accumulation capacitance of $460 \mathrm{nF} . \mathrm{cm}^{-2}$. By thinning down the AlGaN barrier to near $1 \mathrm{~nm}$ using six oxidation/ etching cycles, the threshold voltage is positively shifted and the maximum accumulation capacitance value increases

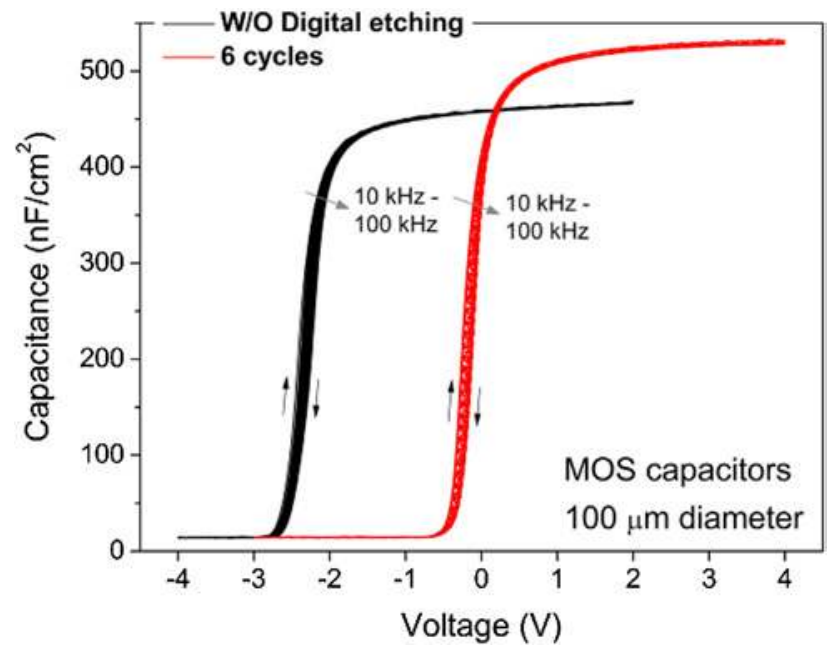

Figure 4 Capacitance-Voltage $\left(C_{\mathrm{GS}}-V_{\mathrm{GS}}\right)$ hysteresis measurements performed on MOS capacitors at frequencies ranging from 10 to $100 \mathrm{kHz}$ with a $10 \mathrm{kHz}$ step.

to $530 \mathrm{nF} . \mathrm{cm}^{-2}$. Using the equation: $D_{\mathrm{it}}=C_{\mathrm{MOS}} \cdot \Delta V_{\mathrm{TH}} / q[2$, 6], the extracted traps density $\left(D_{\mathrm{it}}\right)$ for the reference sample without digital etching is estimated to be $3.71 \times 10^{11} \mathrm{~cm}^{-2} \mathrm{eV}^{-1}$. For the gate recessed sample, using six cycles of digital etching, the estimated $D_{\text {it }}$ was as low as $1.49 \times 10^{11} \mathrm{~cm}^{-2} \mathrm{eV}^{-1}$. This indicates that there is no major damage induced by the digital etching process. Due to the low thickness of the $\mathrm{SiO}_{\mathrm{x}}-\mathrm{PECVD}$ dielectric layer used in this study $(7 \mathrm{~nm})$, the $C-V$ two-step behavior, as previously reported by Yatabe et al. [15], is not observed in our reference sample, even at higher voltage (up to $+6 \mathrm{~V}$ ). Moreover, a catastrophic dielectric breakdown was observed at a voltage around $+6.5 \mathrm{~V}$. This dielectric breakdown was also confirmed by the large increase in the dielectric leakage current after the dielectric breakdown.

Pulsed $I_{\mathrm{DS}}-V_{\mathrm{DS}}$ characteristics were performed on the normally-off MOSHEMT device, achieved using AlGaN barrier digital etching. The measurement pulse width was $500 \mathrm{~ns}$ and the period was fixed to $10 \mathrm{~ms}$. The results, as shown in Fig. 5, demonstrate a negligible gate lag and a low drain lag, below $8 \%$, for a drain voltage of up to $+40 \mathrm{~V}$. These results strongly support the high $\mathrm{SiO}_{\mathrm{x}} / \mathrm{AlGaN}$ interface quality and that no damage was induced by the proposed digital etching process.

4 Conclusions In summary, a normally-off MOSHEMT device with extremely low hysteresis was demonstrated by using an ultra-thin $\mathrm{Al}_{0.45} \mathrm{Ga}_{0.55} \mathrm{~N}$ barrier layer. The electrical characterizations show a pinch-off voltage $\left(V_{\mathrm{p}}\right)$ of $+1.1 \mathrm{~V}$, a threshold voltage of $+0.3 \mathrm{~V}$ at $I_{\mathrm{DS}}=1 \mathrm{~mA} \mathrm{~mm}^{-1}$, a maximum drain current of $460 \mathrm{~mA}$ $\mathrm{mm}^{-1}$, and a low gate and drain leakage current. The device also shows an $I_{\mathrm{ON}} / I_{\mathrm{OFF}}$ ratio higher than $10^{9}$ and a Subthreshold slope of $87 \mathrm{mV} \mathrm{dec}^{-1}$. From $C-V$ and $I_{\mathrm{DS}}-V_{\mathrm{GS}}$ hysteresis measurements, a $D_{\mathrm{it}}$ value as low as $1.49 \times 10^{11} \mathrm{~cm}^{-2} \mathrm{eV}^{-1}$ has been extracted for the sample 


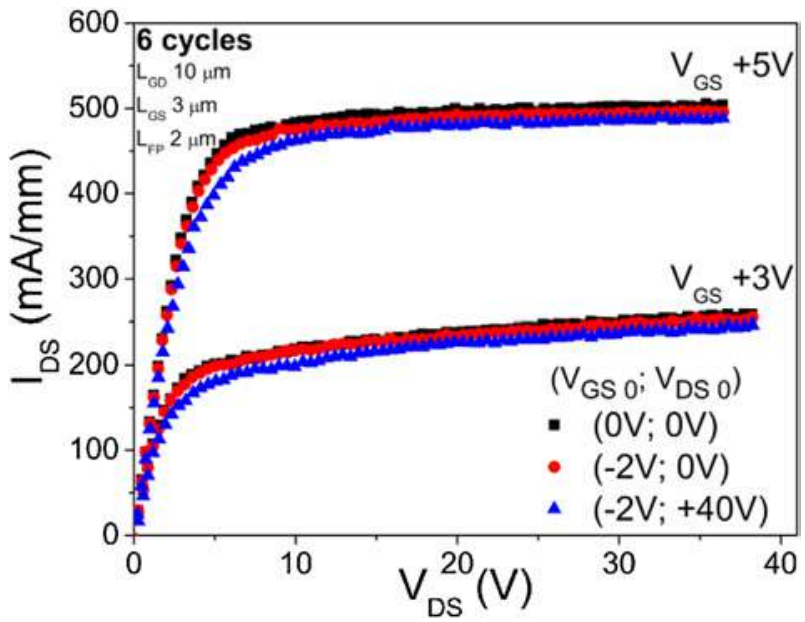

Figure 5 Pulsed $I_{\mathrm{DS}}-V_{\mathrm{DS}}$ curves measured on MOSHEMT device with six cycles of digital etching. Pulse width $=500 \mathrm{~ns}$, period $=10 \mathrm{~ms}$.

with the gate digital etching recess. All these results confirm the low damage induced by the digital etching recess at the $\mathrm{SiO}_{\mathrm{X}} / \mathrm{AlGaN}$ interface. The usage of initial thin $\mathrm{Al}_{0.45} \mathrm{Ga}_{0.55} \mathrm{~N}$ barrier reduces the recess time by digital etching required for this critical step. This approach could be used for the monolithically integration of enhancement and depletion (E/D) mode GaN devices on the same wafer, which will simplify drastically circuit design.

Acknowledgements Authors would like to acknowledge Caroline Roy, Adrien Cutivet and all LNN staff for their contributions in microfabrication process, pulsed characterizations and for fruitful discussions. LN2 is a joint International Research Laboratory (Unité Mixte Internationale UMI 3463) funded and cooperated by CNRS (France) and Université de Sherbrooke (Canada) as well as INSA Lyon, ECL, CPE, Université Grenoble Alpes (UGA), as well as the French national nanofabrication network RENATECH.

\section{References}

[1] Z. Tang, Q. Jiang, Y. Lu, S. Huang, S. Yang, X. Tang, and K. J. Chen, 600-V normally off $\mathrm{SiN}_{\mathrm{x}} / \mathrm{AlGaN} / \mathrm{GaN}$ MIS-HEMT with large gate swing and low current collapse, IEEE Electron. Device Lett. 34(11), 1373-1375 (2013).

[2] Y. Wang, M. Wang, B. Xie, C. P. Wen, J. Wang, Y. Hao, W. $\mathrm{Wu}, \mathrm{K}$. J. Chen, and Bo Shen, High-performance normallyoff $\mathrm{Al}_{2} \mathrm{O}_{3} / \mathrm{GaN}$ MOSFET using a wet etching-based gate recess technique, IEEE Electron Device Lett. 34(11), 1370-1372 (2013).

[3] Z. Xu, J. Wang, Y. Cai, J. Liu, Z. Yang, X. Li, M. Wang, Z. Yang, Bin Xie, M. Yu, W. Wu, X. Ma, J. Zhang, and Y. Hao, $300{ }^{\circ} \mathrm{C}$ operation of normally-off $\mathrm{AlGaN} / \mathrm{GaN}$ MOSFET with low leakage current and high on/off current ratio, Electron. Lett. 50(4), 315-316 (2014).
[4] T. Oka and T. Nozawa, AlGaN/GaN recessed MIS-Gate HFET with high-threshold-voltage normally-off operation for power electronics applications, IEEE Electron Device Lett. 29(7), 668-670 (2008).

[5] S. Huang, S. Yang, J. Roberts and K. J. Chen, Threshold voltage instability in $\mathrm{Al}_{2} \mathrm{O}_{3} / \mathrm{GaN} / \mathrm{AlGaN} / \mathrm{GaN}$ metal-insulator-semiconductor high-electron mobility transistors, Jpn. J. Appl. Phys. 50, 110202 (2011).

[6] Z. Xu, J. Wang, J. Liu, C. Jin, Y. Cai, Z. Yang, M. Wang, M. Yu, B. Xie, W. Wu, X. Ma, J. Zhang, and Y. Hao, Demonstration of normally-off recess-gated AlGaN/GaN MOSFET using GaN cap layer as recess mask, IEEE Electron Device Lett. 35(12), 1197-1199 (2014).

[7] S. Liu, S. Yang, Z. Tang, Q. Jiang, C. Liu, M. Wang, and K. J. Chen, $\mathrm{Al}_{2} \mathrm{O}_{3} / \mathrm{AlN} / \mathrm{GaN}$ MOS-channel-HEMTs with an AlN interfacial layer, IEEE Electron Device Lett. 35(7), 723-725 (2014).

[8] T. E. Hsieh, E. Y. Chang, Y. Z. Song, Y. C. Lin, H. C. Wang, S. C. Liu, S. Salahuddin, and C. C. Hu, Gate recessed quasinormally OFF $\mathrm{Al}_{2} \mathrm{O}_{3} / \mathrm{AlGaN} / \mathrm{GaN}$ MIS-HEMT with low threshold voltage hysteresis using PEALD AlN interfacial passivation layer, IEEE Electron Device Lett. 35(7), 732-734 (2014).

[9] Y. Uemoto, M. Hikita, H. Ueno, H. Matsuo, H. Ishida, M. Yanagihara, T. Ueda, T. Tanaka, and D. Ueda, Gate Injection Transistor (GIT) — A Normally-Off AlGaN/GaN Power Transistor Using Conductivity Modulation, IEEE Trans. Electron Devices 54(12), 3393-3399, (2007).

[10] O. Hilt, A. Knauer, F. Brunner, E. Bahat-Treidel, and J. Würfl, Normally-off AlGaN/GaN HFET with p-type Ga gate and AlGaN buffer, 22nd International Symposium on Power Semiconductor Devices \& IC's (ISPSD), Hiroshima, pp. 347-350 (2010)

[11] H. Hahn, G. Lukens, N. Ketteniss, H. Kalisch, and A. Vescan, Recessed-gate enhancement-mode $\mathrm{AlGaN} / \mathrm{GaN}$ heterostructure field-effect transistors on $\mathrm{Si}$ with record DC performance, Appl. Phys. Express 4, 114102 (2011).

[12] Y. Wang, M. Wang, B. Xie, C. P. Wen, J. Wang, Y. Hao, W. $\mathrm{Wu}, \mathrm{K}$. J. Chen, and B. Shen, High-performance normally-off $\mathrm{Al}_{2} \mathrm{O}_{3} / \mathrm{GaN}$ MOSFET using a wet etching-based gate recess technique, IEEE Electron Device Lett. 34(11), 1370-1372 (2013).

[13] A. Lorenz, J. Derluyn, J. Das, K. Cheng, S. Degroote, F. Medjdoub, M. Germain, and G. Borghs, Influence of thermal anneal steps on the current collapse of fluorine treated enhancement mode SiN/AlGaN/GaN HEMTs, Phys. Status Solidi C 6(S29), S996-S998 (2009).

[14] A. Chakroun, H. Maher, E. Al Alam, A. Souifi, V. Aimez, R. Ares, and A. Jaouad, Optimized pre-treatment process for MOS-GaN devices passivation, IEEE Electron Device Lett. 35(3), 318-320 (2014).

[15] Z. Yatabe, Y. Hori, W.-C. Ma, J. T. Asubar, M. Akazawa, T. Sato, and T. Hashizume, Characterization of electronic states at insulator/(Al)GaN interfaces for improved insulated gate and surface passivation structures of GaN-based transistors, Jpn. J. Appl. Phys. 53, 100213 (2014). 